\title{
LIMBERG FLAP VERSUS EXCISION WITH PRIMARY CLOSURE IN PILONIDAL SINUS
}

\author{
By \\ Sawsan Soliman Mohamed and Mohamed O. Alfy \\ Department of General Surgery, Faculty of Medicine (Girls), Al-Azhar University \\ Corresponding author: Sawsan Soliman Mohamed,
}

Mobile: 01001464690, E-mail: Dr.sawsan_soliman@yahoo.com

\begin{abstract}
Background: Pilonidal sinus disease (PNS) is a potentially debilitating condition. It was first described by Anderson in 1847 and is often seen in the intergluteal region and can cause loss of work time. Several procedures have been advocated for treatment and the fact that no single procedure is superior in all respect.
\end{abstract}

Objective: This study aimed to compare the outcomes of excision and primary closure versus Limberg-flap (LF) techniques.

Patients and methods: This randomized, prospective observational study was carried out at the Department of surgery, Al-Zahraa University Hospital, Al-Azhar University, Cairo, Egypt over 2 years (January 2018 to January 2020) on 60 patients out of which 30 underwent rhomboid excision with Limberg flap reconstruction (group A) and 30 underwent excision with primary closure (group B). Post-operative follow up was done till 12 months and complications were recorded.

Results: There was no statistical difference between the two groups as regards demographic data, partial wound dehiscence, and time to complete healing. There was a statistically significant difference between the two groups as regards wound complications (3.3\% in group A versus $20.0 \%$ in group B) and the recurrence rate $(13.3 \%$ in group $\mathrm{B}$ versus $0 \%$ in group $\mathrm{A})$.

Conclusions: Limberg flap method for the pilonidal sinus is a better choice than midline closure after elliptical excision in terms of postoperative wound complications and recurrence.

Key Words: Pilonidal sinus; Limberg flap; Primary closure.

\section{INTRODUCTION}

Pilonidal sinus disease (PNS) is a common and often debilitating infectious and inflammatory condition of the gluteal cleft and sacrococcygeal region. It is characterized by sinus and abscess formation, typically in association with midline openings that entrap hair and debris (Kumar et al., 2017).

Patients may have significant pain, drainage, and bleeding. Chronicity and recurrence are common. The disease process can range in severity from small, asymptomatic pits to multiple tracts and fistulization away from the midline (Grabowski et al., 2019).

The disease carries high postoperative morbidity and patient discomfort Karydakis suggested three main factors interacting to produce disease namely hair, force, and vulnerability like obesity and family history (Singh et al., 2017). Some researchers have proposed that pilonidal sinus may be the result of a congenital pilonidal dimple. A deep natal cleft is a favorable environment for 
sweating, maceration, bacterial contamination, and penetration of hairs. Thus, for treatment and prevention, these causative factors must be eliminated (Meena et al., 2019).

Although PNS can be treated using several defined conservative and surgical methods, recurrence rates remain high. Complete removal of the pilonidal sinus or sinuses and appropriate reconstruction can lead to successful recovery (Yildiz et al., 2013).

For decades, standard definitive care has consisted of excision with either secondary healing or primary closure of the wound; these approaches were originally derived largely from military hospital experience with Jeep riders' disease (Fitzpatrick et al., 2013).

Although numerous surgical techniques have been reported in the literature, there is still no consensus for the ideal method for the treatment of PNS from abscess drainage to complex advanced off-midline flap mobilizations (Arslan et al., 2016).

Modification of the midline and positioning of the incision scar to the cleft is the most important factor in wound healing; also, a recent Cochrane study reported that off-midline closure techniques should be the standard treatment method in PNS disease (Agcaoglu et al., 2019).

Among these flap techniques, the LF technique has gained popularity and favor of many surgeons because they excise the underlying disease, provide healthy tissue coverage of the cavity without tension and are associated with low recurrence (by flattening and lateralizing the gluteal cleft, respectively) and complication rates (Can et al., 2010).

Our aim in this study was to prospectively compare early results in patients with pilonidal sinus treated with either Limberg flap rotation (LF) or excision with primary closure.

\section{PATIENTS AND METHODS}

This randomized, prospective doubleblind clinical study was carried out at the Department of Surgery, Al-Zahra University Hospital, Al-Azhar University, Cairo, Egypt over 2 years (January 2018 to January 2020). Our institutional review board approved this study under the Helsinki Declaration.

Written informed consents were obtained from patients who were scheduled for elective PNS surgery (informing about the procedure, its complications, and the incidence of recurrence), both sexes patients were aged between 18 and 60 years, with ASA I or II.

\section{Exclusion criteria:}

Patients who refused to participate in the study, local infection at the site of operation, patients with a psychiatric disease or poor hygiene, (ASA) physical status $\geq 3$ e.g. cardiac disease, pregnant woman, history of drug abuse, uncontrolled diabetes mellitus, patients with the unstable cardiorespiratory disorder, patients with hepatic and renal insufficiency.

\section{Patients were classified randomly into two equal groups:}

Group A: Underwent pilonidal surgery by excision and closure using the Limberg flap technique. 
Group B: Underwent pilonidal sinus surgery by excision with primary closure only.

All were subjected to detailed personal data, risk factors, history of present illness, general and local examination, and laboratory investigations (preoperative preparation).

\section{Surgical technique:}

Excision and primary closure: The excision site was marked $1 \mathrm{~cm}$ away from the sinus. Then an elliptical incision was made that extended to the post sacral fascia. The tissue was resected, and proper hemostasis was done using minimum electrocautery. Then the wound was closed in layers and a vacuum drain (Redivac) was placed in a subcutaneous plane.
Limberg flap technique: We followed the surgical technique which was discussed by Singh et al. (2017).

\section{Statistical analysis:}

Data were collected, revised, coded, and entered into the Statistical Package for the Social Science (IBM SPSS) version 23 (IBM Corp., Armonk, New York, USA). The quantitative data were presented as mean, standard deviations, and ranges and were compared by independent t-test. Qualitative data were presented as numbers and percentages and were compared by the Chi-square test (X2) or Fisher's exact test. So, the p-value was considered significant at $\mathrm{p}<0.05$.

\section{RESULTS}

Sixty patients were included in this study, 30 patients underwent excision with Limberg flap (group A) and 30 patients underwent excision with primary closure (group B). Patients were followed up for one year.

There was no statistical difference between the two groups as regards demographic data, partial wound dehiscence, and time to complete healing (Table 1).
Operative time, wound infection and recurrence showed a statistically significant difference between the two groups. Recurrence occurred in 4 patients in group B (13.3\%) and nil in group A. Total wound dehiscence and flap necrosis did not occur in any patient. Wound infection occurred in one patient in group A $(3.3 \%)$ and 6 patients in group B (20.0\%) (Table 1). 
Table (1): Comparison between the two groups (Mean \pm SD)

\begin{tabular}{|c|c|c|c|}
\hline $\begin{array}{ll}\text { Parameters } & \text { Groups } \\
\end{array}$ & $\begin{array}{l}\text { Group A } \\
(\text { no. }=30)\end{array}$ & $\begin{array}{r}\text { Group B } \\
(\text { no. }=30)\end{array}$ & P-value \\
\hline $\begin{array}{l}\text { Age } \\
\text { Mean } \pm \text { SD } \\
\text { Range }\end{array}$ & $\begin{array}{c}32.51 \pm 6.72 \\
16-43\end{array}$ & $\begin{array}{c}33.29 \pm 7.43 \\
18-40\end{array}$ & $>0.05$ \\
\hline $\begin{array}{l}\text { Sex } \\
\text { Males } \\
\text { Females }\end{array}$ & $\begin{array}{l}23(76.7 \%) \\
7(23.3 \%)\end{array}$ & $\begin{array}{l}24(80.0 \%) \\
6(20.0 \%)\end{array}$ & $>0.05$ \\
\hline Wound infection & $1(3.3 \%)$ & $6(20.0 \%)$ & 0.044 \\
\hline Partial wound dehiscence & $0(0.0 \%)$ & $2(6.7 \%)$ & $>0.05$ \\
\hline $\begin{array}{l}\text { Mean operative time } \\
\text { Mean } \pm \text { SD } \\
\text { Range (minutes) }\end{array}$ & $\begin{array}{l}36.3 \pm 3.24 \\
40-52\end{array}$ & $\begin{array}{c}24.93 \pm 3.06 \\
20-30\end{array}$ & $<0.001$ \\
\hline $\begin{array}{l}\text { Time to healing } \\
\text { Mean } \pm \text { SD } \\
\text { Range (days) }\end{array}$ & $\begin{array}{c}22.32 \pm 2.35 \\
18-27\end{array}$ & $\begin{array}{c}23.51 \pm 2.87 \\
20-30\end{array}$ & $>0.05$ \\
\hline Recurrence & $0(0.0 \%)$ & $4(13.3 \%)$ & 0.038 \\
\hline
\end{tabular}

\section{DISCUSSION}

This study compared between primary midline closure technique and the Limberg flap in pilonidal sinus disease in which there was no significance between two groups related to age.

This study showed high significance between two groups in operative time and this is because excision with reconstruction procedures is more technically demanding.

Kumar et al. (2017) have published a median operative time of $124.2 \mathrm{~min}$. for the Limberg flap group against $38.7 \mathrm{~min}$. for the primary midline closure group and the difference has been found to be significant. They reported the important advantages of the LF procedure as quick healing time, a short length of hospital stays, early return to normal activities, and low complication and recurrence rates.

Recurrence is the main problem in the treatment of pilonidal sinus. In our study, the recurrence rate in primary closure was
$13.3 \%$ while no recurrence was reported in the Limberg flap group.

Several flap techniques have been described with recurrence rates ranging between zero and 6-8\% (Spycha and Murawa, 2014).

Meena et al. (2019) determined a recurrence rate of $3.33 \%$ in the Limberg flap method and $26.67 \%$ in the primary closure method (P-value <0.05) and recommended the Limberg flap method for primary pilonidal disease with low morbidity rates as compared to primary closure.

A retrospective study was done by Akin et al. (2010) has shown that the recurrence rate was statistically higher in the classical group than in the modified Limberg flap group.

A recent meta-analysis demonstrating a higher recurrence rate in those with primary midline closure versus offmidline closure (Stauffer et al., 2018).

Karaca et al. (2012) reported that the Limberg Flap group provided better 
postoperative pain score (visual analogue scale: VAS), complication rate, time to discontinuation of analgesics, and painless sitting.

In our study, wound infection was $3.3 \%$ for the Limberg flap group, and $20 \%$ for the primary closure group which was statistically significant.

Singh et al. (2017) reported, in his study for LF repair, that seroma development to be $6.2 \%$ and superficial surgical site infection $3.1 \%$.

\section{CONCLUSION}

- Limberg flap method for pilonidal disease is a better choice than primary closure in terms of postoperative wound complications and recurrence. Post-surgical counseling for hair removal was very important to prevent a recurrence.

- Further studies are necessary with a larger volume sample and longer follow up period.

Conflict of Interest: No conflict of interest was declared by the authors.

Financial Disclosure: The authors declared that this study has received no financial support.

\section{REFERENCES}

1. Agcaoglu O., Dural A.C., Ercetin C., Tezcaner T., Kirnap M. and Anuk T. (2019): Comparison of Cleft Lift and Limberg Flap Techniques for Pilonidal Sinus Surgery. Eastern J Med., 24(3): 320-324.

2. Akin M, Leventoglu S, Mentes BB, Bostanci H, Gokbayir H, Kilic K, Ozdemir E and Ferahkose Z. (2010): Comparison of the classic Limberg flap and modified Limberg flap in the treatment of pilonidal sinus disease: a retrospective analysis of 416 patients. Surg Today, 40(8): 757- 62.

3. Arslan, S., Karadeniz, E., Ozturk, G., Aydinli, B., Bayraktutan, M. C. and Atamanalp, S.S. (2016): Modified Primary Closure Method for the Treatment of Pilonidal Sinus. The Eurasian Journal of Medicine, 48(2): 8489.

4. Can MF, Sevinc MM, Hahcerliogullari O, Yilmaz M. and Yagci G. (2010): Multicentre prospective randomized trial comparing modified Limberg flap transposition and Karydakis flap reconstruction in patients with sacrococcygeal pilonidal disease. Am J Surg., 200(3):318-27.

5. Fitzpatrick EB, Chesley PM, Oguntoye MO, Maykel JA, Johnson EK and Steele SR. (2014): Pilonidal disease in a military population: how far have we really come? Am J Surg., 207(6):907914.

6. Grabowski J., Oyetunji T.A., Goldin A.B., Baird R., Gosain A., Lal D.R., Kawaguchi A., Downard C., Sola J.E., Arthur L.G., Shelton J., Diefenbach K.A., Williams R.F. and Ricca R.L. (2019): The management of pilonidal disease: A systematic review. Journal of Pediatric Surgery, 54(11):2210-2221.

7. Karaca T, Yoldas, O, Bilgin BÇ, Ozer S, Yoldas, S and Karaca NG. (2012): Comparison of short-term results of modified Karydakis flap and modified Limberg flap for pilonidal sinus surgery. Int S Surg., 10(10):601-6.

8. Kumar R, Hastir A, Walia RS, Goyal Sand Kaur A. (2017): Prospective randomized study of surgical treatment of pilonidal sinus; primary midline closure after elliptical excision versus rhomboid excision with Limberg flap reconstruction versus open excision and 
healing by secondary intention. Int Surg J., 4:3646-51.

9. Meena OK, Kalwaniya DS, Arya SV, Kuppuswami M, Bajwa JS, Pradhan RS., Narayan A., Mahadevan R. and Verma M.K. (2019): A comparative study of excision with primary closure versus Limberg flap in pilonidal sinus. Int Surg J., 6(12):1-8.

10. Singh PK., Gohil RK., and Saxena, N. (2017): Limberg flap procedure for sacrococcygeal pilonidal sinus: a prospective study. Int Surg J., 4(7):22382242.

11. Spycha A and Murawa D. (2014): The Limberg flap procedure in the treatment of pilonidal cyst disease of the sacrum initial report. Pol Przegl Chir., 86(6):25762.
12. Stauffer VK, Luedi MM, Kauf $P$, Schmid M., Diekmann M., Wieferich K., Schnüriger B. and Doll D. (2018): Common surgical procedures in pilonidal sinus disease: A meta-analysis, merged data analysis, and comprehensive study on recurrence. Scientific reports, 8(1):3058.

13. Yildiz, M. K., Ozkan, E., Odabaşı, H. M., Kaya, B., Eriş, C., Abuoğlu, H. H., Günay, E., Fersahoglu, M. M. and Atalay, S. (2013): Karydakis flap procedure in patients with sacrococcygeal pilonidal sinus disease: experience of a single center in Istanbul. The Scientific World Journal, 807027. 


\section{رفرف ليمبرغ مقابل الاستئصال مع الإغلاق الأولى فى الجيب الشعرى}

سوسن سليمان محمد سليمان، محمد عمر محمد الألفى

قسم الجراحة العامة، كلية طب بنات الأزهر

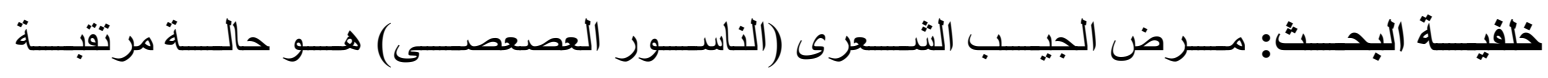

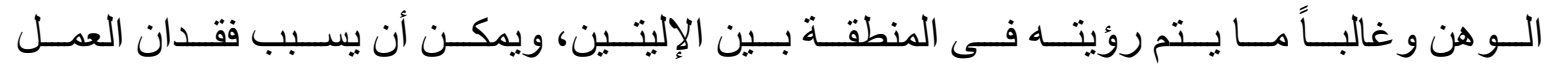

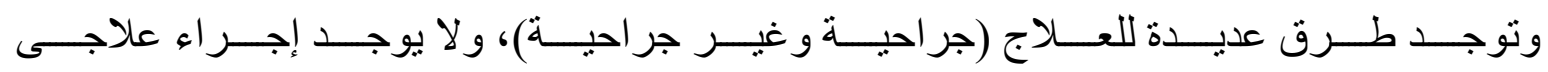

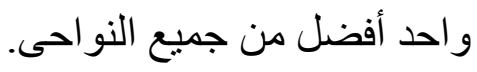

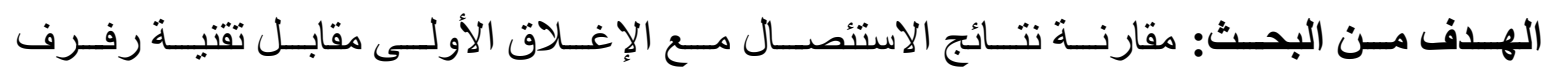
ليمبرغ.

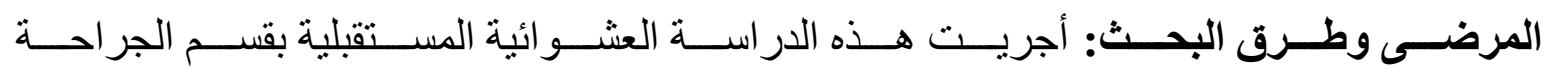

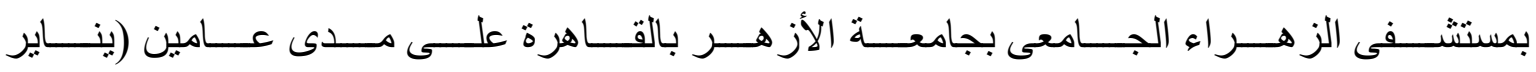

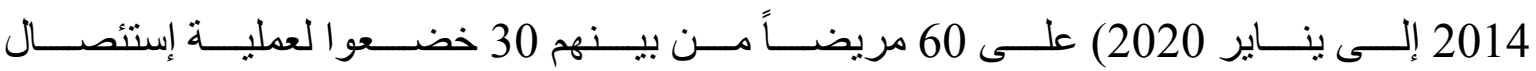

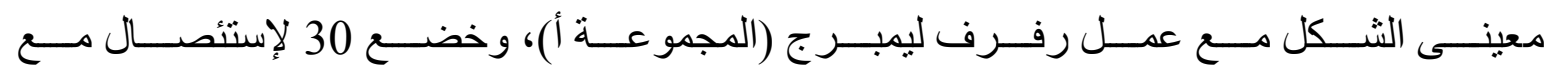
الإغلاق الأولى (المجمو عة ب)، وتمت متابعة ما بعد الجر احة حتى 12 شهر.

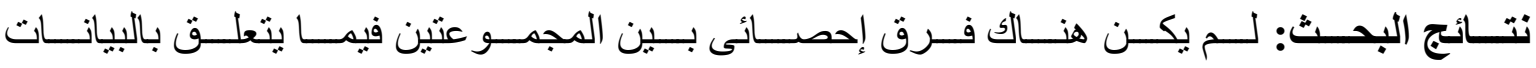

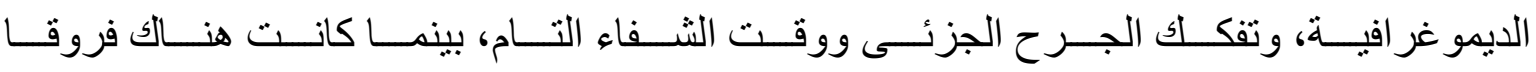

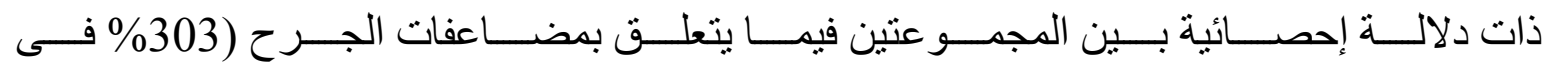

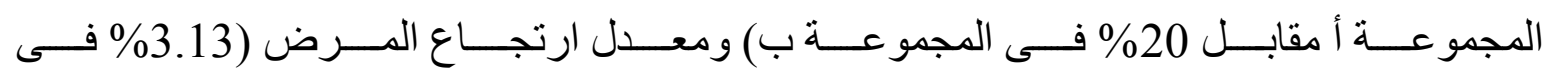
المجمو عة ب مقابل 0\% فى المجموعة أب أ).

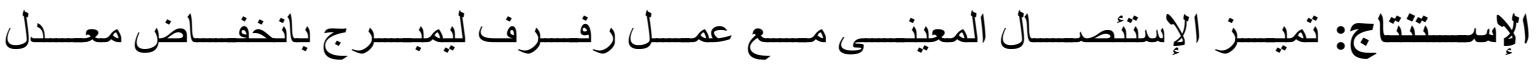

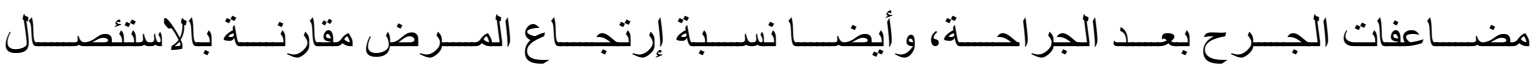

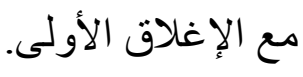

